\title{
BMJ Open Outpatient antibiotic use in Dutch infants after 10-valent pneumococcal vaccine introduction: a time- series analysis
}

\author{
Alexandre C Fortanier, ${ }^{1}$ Roderick P Venekamp, ${ }^{1}$ Rebecca K Stellato, ${ }^{1}$ \\ Elisabeth A M Sanders, ${ }^{2,3}$ Roger A M J Damoiseaux, ${ }^{1}$ Arno W Hoes, ${ }^{1}$ \\ Anne M Schilder ${ }^{1,4}$
}

To cite: Fortanier AC, Venekamp RP, Stellato RK, et al. Outpatient antibiotic use in Dutch infants after 10-valent pneumococcal vaccine introduction: a timeseries analysis. BMJ Open 2018;8:e020619. doi:10.1136/ bmjopen-2017-020619

- Prepublication history for this paper is available online. To view these files, please visit the journal online (http://dx.doi org/10.1136/bmjopen-2017020619).

Received 14 November 2017 Revised 25 April 2018 Accepted 15 May 2018
Check for updates

${ }^{1}$ Julius Center for Health Sciences and Primary Care, University Medical Center, Utrecht, The Netherlands ${ }^{2}$ Department of Paediatric Immunology and Infectious Disease, University Medical Center, Utrecht University, Utrecht, The Netherlands

${ }^{3}$ Centre for Infectious Disease Control, National Institute of Public Health and the Environment (RIVM), Bilthoven, The Netherlands

${ }^{4}$ evidENT, Ear Institute, University College London, London, UK

Correspondence to

Alexandre C Fortanier; a.c.fortanier@umcutrecht.nl

\section{ABSTRACT}

Objective This population-based cohort study assesses the impact of switching from a 7-valent pneumococcal conjugate vaccine (PCV) to a 10-valent PCV on outpatient antibiotic use in Dutch infants, and whether geographical vaccination coverage modifies this association.

Setting and participants We extracted 2006-2013 anonymised antibiotic purchase data of 255154 Dutch infants aged below 2 years from Achmea Health, a health insurance fund covering $28 \%$ of the national population. Design and main outcome measure Changes in monthly antibiotic use from 2006-2011 (PCV7) to 2011-2013 (PCV10) were estimated using time-series analysis accounting for seasonality and autocorrelation. Interaction terms for vaccination coverage (categorised into seven groups) and period were added to the model to test whether this association was vaccination coveragedependent.

Results 275337 antibiotic courses were used by 119078 infants (461 352 person-years). PCV10 introduction was associated with a modest $1.6 \%$ overall reduction in antibiotic use (purchase rate ratio: $0.98,95 \% \mathrm{Cl}: 0.98$ to 0.99 ). Our model showed a significant difference in time trend in antibiotic use after PCV10 introduction $(p=0.0084)$ with an increase in prescriptions in the PCV7 period (slope: $0.0023 /$ month, $95 \% \mathrm{Cl}$ : -0.0001 to 0.0047 ) versus a decline in the PCV10 period (slope: -0.0089 / month, $95 \% \mathrm{Cl}$ : -0.0150 to -0.0029$)$. There was no evidence that PCV vaccination coverage affected this association, but since the largest rate ratios were observed in municipalities with the lowest vaccine coverage and had very wide accompanying $\mathrm{Cls}$, our study might have insufficient power to detect such an association.

Conclusions Switching from PCV7 to PCV10 was associated with a modest decline in outpatient antibiotic use in Dutch infants.

\section{INTRODUCTION}

Antibiotics represent the most commonly prescribed therapeutic agents in childhood worldwide. Up to $90 \%$ of all childhood antibiotics are prescribed in primary care, ${ }^{12}$ and $80 \%$ of those are for respiratory tract infections. ${ }^{3}$
Strengths and limitations of this study

- Anonymised nationwide outpatient antibiotic purchase data were extracted from a large insurance fund that provides obligatory health insurance.

- Quasi-experimental approach using interrupted time-series analysis to study longitudinal effects of interventions using observational data.

- To reduce potential confounding, regression analyses were used to assess whether vaccination coverage modified the association between vaccination and antibiotic purchases.

- There was a potential for unmeasured confounding due to the observational nature of the study.

- This study did not include data from before 2006 and with the most prominent decline seen in 2013, future work should include longer follow-up data.

Its routine use for common primary care infections favours the emergence of antibiotic resistance and with increasing resistance effective treatment of bacterial infections is threatened. ${ }^{4}$ Previous research has shown that introduction of pneumococcal conjugate vaccines (PCV) in childhood reduced pneumococcal disease incidence and subsequent antibiotic prescription rates, thereby limiting the spread of antibiotic resistance. ${ }^{5-9}$ These reductions, however, have been reported in countries where either antibiotic use is high, ${ }^{10}$ where childhood respiratory tract infections were already on the decline, ${ }^{11} 12$ or where new guidance on judicious use of antibiotics was introduced during the observational period. ${ }^{13}$

We, therefore, set out to study the impact of switching from a 7-valent PCV to a 10-valent PCV on outpatient antibiotic use in infants in the Netherlands where reliable longitudinal data on outpatient antibiotic purchases are held by the Dutch insurance 
funds that provide obligatory health insurance, ${ }^{14}$ and where judicious antibiotic use has been promoted since the 1980s resulting in low antibiotic prescribing and resistance rates. ${ }^{15-17}$ In addition, vaccination coverage is closely monitored across all Dutch municipalities by the National Institute for Public Health and the Environment (RIVM) ${ }^{18}$ allowing us to study whether geographical PCV coverage modifies this association.

\section{PATIENTS AND METHODS}

In the Dutch healthcare system, all citizens have a basic obligatory healthcare insurance which covers costs of medication. ${ }^{14}$ In this observational cohort study, we used anonymised outpatient antibiotic purchase data from Achmea Health, one of the largest health insurance funds covering 4.8 million individuals (28\% of the Dutch population). The population insured by Achmea Health represents the urbanised area of the Netherlands with regard to age, sex and socioeconomic status. ${ }^{14}$ All children born between January 2006 and February 2013 and registered with Achmea Health within the first 6 months of life were included and follow-up started from birth onwards. With an annual birth cohort ranging from 185.057 (in 2006) to 171.341 (in 2013), our study population covered $19 \%$ of the total Dutch birth cohort. They were followed up until sensor date, that is until 2 years of age, or until they left the insurance fund or until the end of our study period (31 December 2013).

The Dutch National Immunisation Program (NIP) introduced PCV7 for all infants born as from 1 April 2006. The NIP switched from PCV7 to PCV10 for infants born as from 1 March 2011. PCV7 and PCV10 initially were given at ages 2, 3, 4 and 11 months. A three-dose schedule at ages 2, 4 and 11 months was implemented for children born as from 1 November 2013. Although PCV vaccination coverage on average has been stable and high at $94.4 \%-95.1 \%$ (median: $94.8 \%$ ) since its introduction in 2006, there is considerable geographical variation across the 393 Dutch municipalities, and PCV vaccination coverage data were available for all municipalities. ${ }^{18}$ We obtained PCV vaccination coverage data for all 393 municipalities as reported by the RIVM in $2012^{1819}$ and categorised municipalities into seven groups $(<70.0 \%$, 2 municipalities with 746 children; $70.0 \%-74.9 \%$, 3 municipalities with 2043 children; $75.0 \%-79.9 \%, 5$ municipalities with 1437 children; $80.0 \%-84.9 \%, 9$ municipalities with 2131 children; 85.0\%-89.9\%, 27 municipalities with 9357 children; 90.0\%-94.9\%, 112 municipalities with 96274 children; $95.0 \%-100.0 \%, 231$ municipalities with 143166 children). Categorisation was done in a stepwise process: we (1) obtained PCV vaccination coverage data by municipality, (2) linked municipality by their unique postal codes, (3) linked the postal code available for every child to a specific municipality and its vaccination coverage (4) allocated a child to one of the seven categories.

We used Anatomical Therapeutic Chemical codes to extract data on the most commonly prescribed antibiotics in respiratory tract infections ${ }^{17}{ }^{20}$ in children in
The Netherlands: amoxicillin (J01CA04), amoxicillin/ clavulanic acid (J01CR02), phenoxymethylpenicillin (J01CE02), pheneticillin (J01CE05), trimethoprim/ sulfamethoxazole (J01EE01), clarithromycin (J01FA09) and azithromycin (J01FA10). Infant antibiotic purchase data were available for 389 of the 393 (99\%) Dutch municipalities.

\section{Patient and public involvement}

There was no patient or public involvement in the study.

\section{Statistical analysis}

The total number of children at risk per month (persontime) and region was calculated using date of birth, postal code, registration date and sensor date for each child in the Achmea Health Database. Using the antibiotic purchase date, the total number of antibiotic purchases per month and region was calculated. Crude monthly antibiotic purchase rates per 1000 child-months and its $95 \%$ CI were calculated by dividing the number of observed antibiotic purchases by the total number of observed child-months for the period 2006-2013 using Poisson exact test. The purchase rate ratio (RR) was calculated per municipality by dividing the antibiotic prescription rate after PCV10 implementation over the rate before PCV10 implementation. The percentage of change as a measure of vaccine impact was calculated by 1 -RR $100 \% .^{21}$

Next, monthly antibiotic purchases were estimated by negative binomial regression analysis, using the natural logarithm of the number of antibiotic purchases per month as the outcome and the natural logarithm of the number of children 'at risk' as an offset variable. The model can be written as: $\ln (\mathrm{Y} t)=\beta_{0}+\beta_{1} \times$ time $+\beta_{2} \times$ factor $($ month $)+\beta_{3} \times$ period $+\beta_{4} \times$ [period $\times$ time $]+\beta_{5} \times[$ lag $]+\beta_{6} \times[$ lag2 $]+\ln [$ offset $]$. Here, $\mathrm{Y} t$ is the mean number of prescriptions per child in month $t$; time is a continuous variable indicating time in months at time $t$ from the start of the observation period; period is an indicator from time $t$ occurring before (period=0; January 2006 to February 2011) or after (period=1; March 2011 to December 2013) the start of PCV10 vaccination that was implemented at month 63 in the series. An interaction between 'time period' was used to assess the level and change after the introduction of PCV10 on antibiotic purchases; a combination of calendar month and 1-month and 2-month lag terms were used to adjust for seasonality and autocorrelation. ${ }^{22}{ }^{23}$ In this model, the intercept $\left(\beta_{0}\right)$ estimates the baseline level of the outcome, mean number of prescriptions per patient per month, at time $0 ; \beta_{1}$ estimates the change in the mean number of prescriptions per patient that occurs with each month before the intervention (ie, the baseline trend); $\beta_{3}$ estimates the level change in the mean monthly number of prescriptions; and $\beta_{4}$ estimates the change in the trend in the mean monthly number of prescriptions per patient after PCV10 introduction (period=1), compared with the monthly trend before. The sum of $\beta_{1}$ and $\beta_{4}$ is the post-PCV10 slope. This model 
is often referred to as interrupted time series analysis. ${ }^{22} \mathrm{~A}$ goodness of fit test was used to compare the model to the observed data. To test whether there was a difference in time trends before and after the introduction of PCV10, we compared this model with one without the period and period $\times$ time effects (assuming the same intercept and slope over time for the two periods) using a likelihood ratio test. Inspection of residuals was performed to detect normality, linearity, homoscedasticity and autocorrelation. $^{22} 23$

In a sensitivity analysis, we excluded the first 2 years of observations (both follow-up time and antibiotic prescriptions) since none of the subjects reached the age of 2 years during this period. In a further sensitivity analysis, coverage was added to the main model, along with its interactions with period and time to assess whether the level and change of antibiotic prescriptions differ by period, time and vaccination coverage. All statistical analyses were performed using SPSS V.24.0 and the R statistical software system V.0.98.1103 (RStudio).

\section{RESULTS}

Over the years 2006-2013, 255154 infants (51\% boys) were followed for 461352 child-years (mean duration of follow-up per child: 21.7 months, SD: 4.9 months). A total of 275337 antibiotics were used in 119078 infants (47\% of infants, of which 55\% were boys). With 201797 courses (73\% of total purchases), amoxicillin was most commonly used. Mean outpatient antibiotic purchase prescription rates during the PCV7 and PCV10 periods were $601(95 \%$ CI: 598 to 604) and 591 (95\% CI: 588 to 595) per 1000 child-years, respectively (table 1 ). These data indicate that PCV10 introduction was associated with a modest reduction in outpatient antibiotic use of $1.6 \% \quad(\mathrm{RR}=0.984$, 95\% CI: 0.977 to 0.992 ).

The goodness of fit test indicated that our time-series model fitted the observed data ( $\mathrm{p}=0.06$, figure 1 ). Modelling allowed for estimation of linear trends over the two periods, with antibiotic rates slightly increasing over the PCV7 period (slope: $0.0023 /$ month, 95\% CI: -0.0001 to 0.0047 ) versus a decline in the PCV10 period (slope:
-0.0089 /month, $95 \%$ CI: -0.0150 to -0.0029$)$. The likelihood ratio test showed a significant difference in time trend after PCV10 introduction $(\mathrm{p}=0.0084)$ (figure 1).

The sensitivity analysis in which the first 2 years of observations (2006 and 2007) were excluded also showed a significant difference in time trend after PCV10 introduction, but with a more or less stable trend in the PCV7 period (slope: $-0.0004 /$ month, 95\% CI: -0.0027 to $0.0020)$ and a more modest decline in the PCV10 period (slope: $-0.0014 /$ month, $95 \%$ CI: -0.0193 to -0.0085 ; likelihood ratio test $\mathrm{p}<0.001$ ).

The observed purchase RRs across the municipalities with varying vaccination coverage are illustrated in figure 2. A sensitivity analysis showed no evidence that PCV vaccination coverage affected the association (all $\mathrm{p}$ values for interaction terms were larger than $\mathrm{p}=0.45$ ).

\section{DISCUSSION}

Our large population-based cohort study shows that replacement of PCV7 by PCV10 is associated with a $1.6 \%$ reduction in outpatient antibiotic use in Dutch infants. This is a far more modest decline than the $7 \%$ and $17.5 \%$ decline observed in a Finnish cluster randomised controlled trial of PCV10 versus placebo and in a study using data from the Finnish social insurance institution. ${ }^{724}$ Importantly, in addition to differences in study design, these Finnish studies assessed the impact of PCV10 in PCV naive children, whereas our study compared PCV10 with PCV7.

So far, two observational studies have assessed the impact of introduction of PCV10 or PCV13 subsequent to PCV7 and focused on antibiotic prescribing for respiratory diseases including acute otitis media. ${ }^{25}$ Gefenaite $e t a l^{25}$ found only a marginal percentage change in amoxicillin, azithromycin and sulfamethoxazole/trimethoprim prescriptions in Dutch infants aged $1(-1.43 \%, 95 \%$ CI: $-2.16 \%$ to $-0.69 \%)$ and 2 years $(-0.80 \%, 95 \% \mathrm{CI}:-1.69 \%$ to $0.10 \%)$, respectively. ${ }^{25}$ They, however, based their findings on information from 60 local pharmacies, and changes in population size over time were not taken into account. ${ }^{25}$ While overcoming these methodological issues, our study results were more

Table 1 Rate of observed antibiotic purchases, * Dutch infants aged under 2 years and changes in rates from PCV7 to PCV10

\begin{tabular}{|c|c|c|c|c|}
\hline & $\begin{array}{l}\text { Number of } \\
\text { observed purchases }\end{array}$ & Person-years & $\begin{array}{l}\text { Rate per } 1000 \\
\text { child-years }\end{array}$ & $95 \% \mathrm{Cl}$ \\
\hline Overall period $†$ & 275337 & 461352 & 597 & 595 to 599 \\
\hline \multirow[t]{2}{*}{ PCV10 } & 116127 & 196406 & 591 & 588 to 595 \\
\hline & Rate ratio & $95 \% \mathrm{Cl}$ & Change (\%) & 95\% Cl¥ \\
\hline
\end{tabular}

*Amoxicillin (J01CA04), amoxicillin/clavulanate (J01CR02), pheneticillin (J01CE05), phenoxymethylpenicillin (J01CE02) and trimethoprim/ sulfamethoxazole (J01EE01), azithromycin (J01FA10), clarithromycin (J01FA09).

†PCV7 period: January 2006 to February 2011; PCV10 period: March 2011 to December 2013.

$\ddagger$ Vaccine impact: percentage of change calculated using (1-rate ratio) $\times 100$.

PCV, pneumococcal conjugate vaccine. 


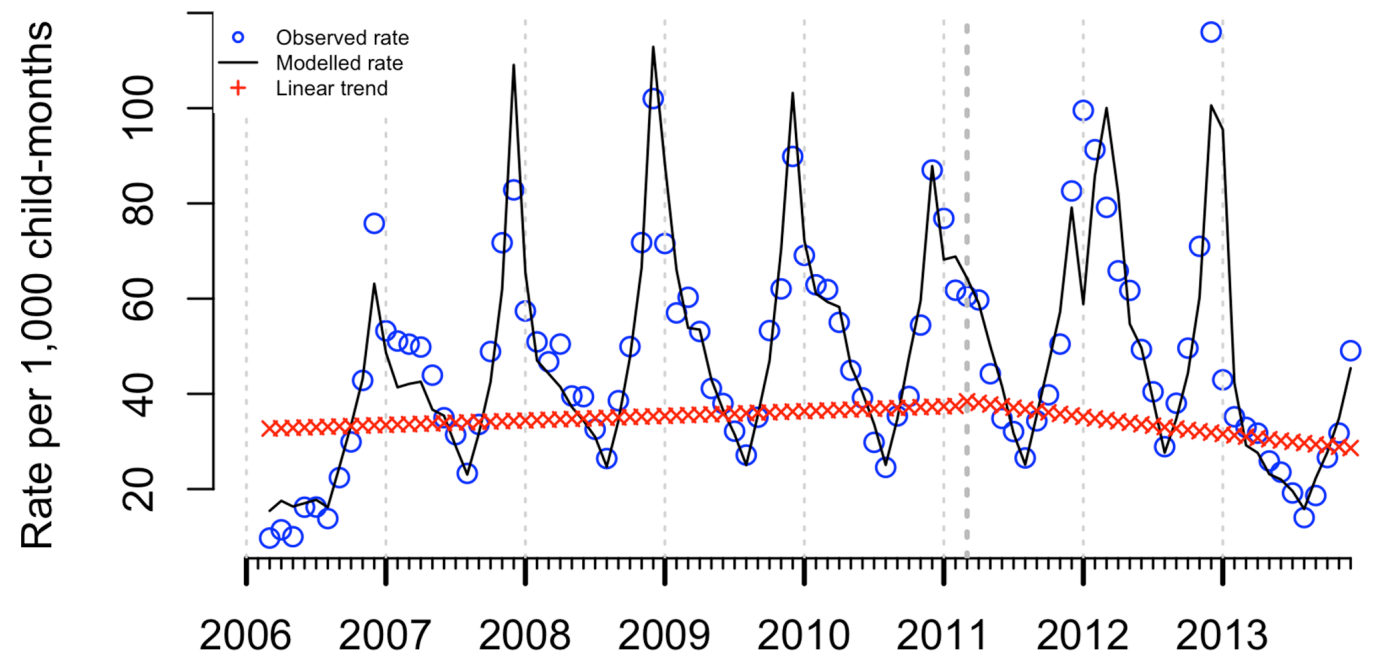

\section{Years}

Figure 1 Observed and estimated antibiotic purchase rates before and after pneumococcal conjugate vaccine 10 implementation in Dutch infants aged under 2 years (rate per 1000 child-months). Observed monthly antibiotic purchase rates per 1000 child-months were calculated by dividing the number of antibiotic purchases by the total number of child-months. Estimated monthly antibiotic purchases were estimated using time-series analysis.

or less similar, with a modest effect on antibiotic purchases. Lau $e t a l^{26}$ studied UK children and found a $2.6 \%$ decline in antibiotic prescriptions specific to acute otitis media after switching from PCV7 to PCV13 in infants. PCV introduction in the Netherlands have led to a decline in pneumonia hospitalisations in children up to 2 years of age $\mathrm{e}^{27}$ which is in line with the observed reductions in childhood invasive pneumococcal disease. ${ }^{28}$ Currently, data on the impact of PCVs on mild-to-moderate respiratory tract infections are, however, lacking. Moreover, any regional differences in the impact of PCV have not been studied, although regional clustering of unvaccinated children have led to outbreaks of, for example, vaccine-preventable measles disease in the Netherlands. ${ }^{29}$

Major strengths of our study are the large sample size, and the completeness and high validity of our dataset: we included infants registered with the health insurance company within the first 6 months of life and with all Dutch citizens having an obligatory basic healthcare insurance that covers costs of medication, our antibiotic data are

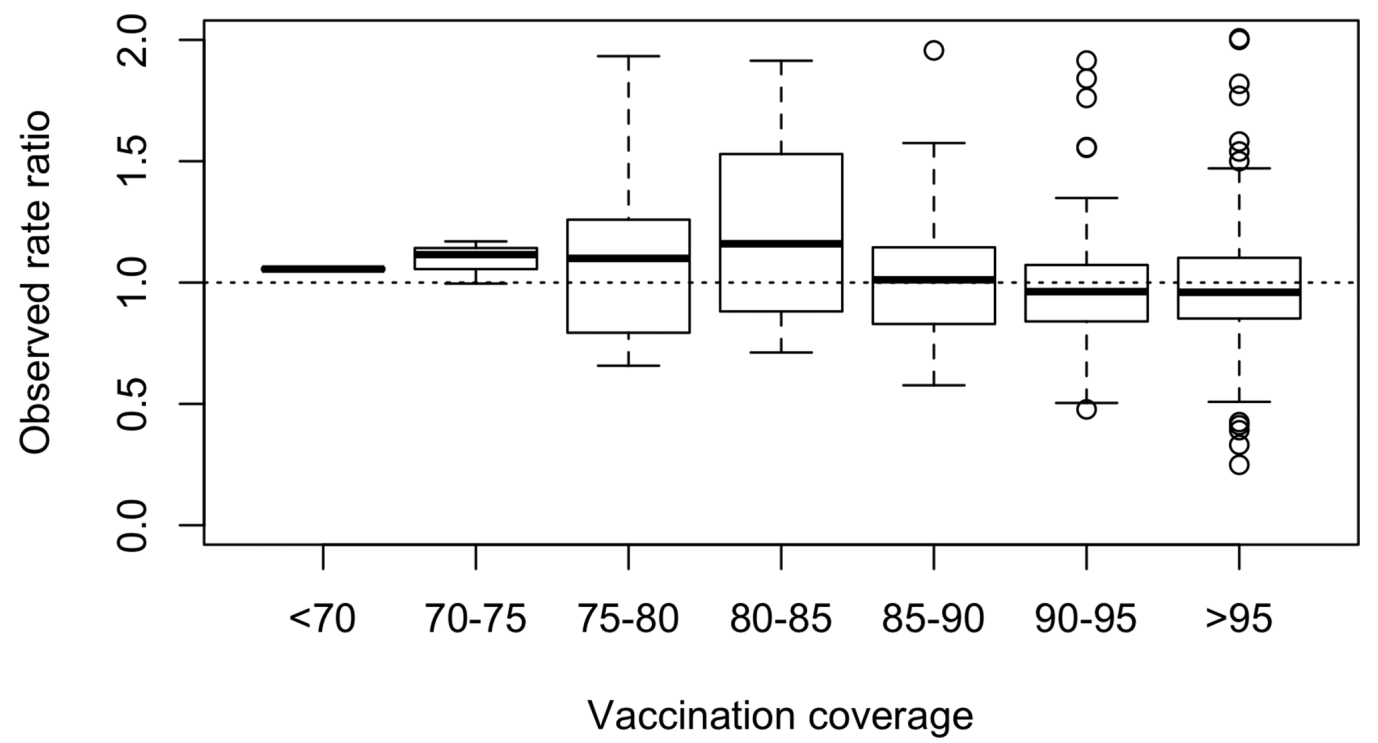

Figure 2 Observed rate ratios across municipalities with varying pneumococcal conjugate vaccine coverage. Vaccination coverage was categorised into seven groups (municipalities with a vaccination coverage $<70 \%$, between $70 \%$ and $75 \%, 75 \%$ and $80 \%, 80 \%$ and $85 \%, 85 \%$ and $90 \%, 90 \%$ and $95 \%$, and $>95 \%$ ). Median purchase rate ratios (RRs) and IQRs for the seven groups are illustrated by box plots. Four outliers were excluded from the graph, but not from the analyses; these four observed RRs were between 3 and 4. 
reliable. ${ }^{14}$ Furthermore, neither new public health initiatives to reduce antibiotic prescribing that could have influenced prescribing practices nor vaccination programmes other than PCV have been implemented during our study period. Finally, our quasi-experimental approach using interrupted time-series analysis makes full use of the longitudinal nature of the data, accounts for preintervention trends and is therefore considered most optimal to study longitudinal effects of interventions using observational data. ${ }^{23}$ Our finding that $\mathrm{PCV}$ vaccination coverage did not modify the association between PCV10 introduction and antibiotic purchases might suggest that herd effects may be sufficiently strong to protect children in municipalities with a lower vaccine coverage against respiratory infections and associated antibiotic use or that the observed reduction is unrelated to PCV10 introduction. Nevertheless, the largest RRs (figure 2) were observed in municipalities with the lowest vaccine coverages and had very wide accompanying CIs. Our study might, therefore, have insufficient power to draw valid conclusions regarding the impact of vaccination coverage.

Limitations of our approach include confounding due to the observational nature of the study: temporal fluctuations in risk factors for childhood respiratory tract infections and subsequent antibiotic prescribing such as breast feeding, household smoking, daycare attendance and differences in viral seasons may have impacted our findings. ${ }^{12}{ }^{30-33}$ Furthermore, as influenza virus infections are linked to excess antibiotic prescribing in children,${ }^{34}$ the peak in antibiotic prescriptions in 2009 might be explained by the 2009 H1N1 pandemic. Second, the available follow-up time after PCV10 introduction (ie, 2.5 years) is a limitation of our study and with the most prominent decline seen in 2013 (figure 1), future work should include longer follow-up data to fully quantify the impact of PCV10 on childhood antibiotic use. Third, antibiotic prescriptions issued between the date of birth and date of registration at the health insurance fund are missing from our dataset. With the majority of antibiotic prescriptions issued in children aged 3 months and above and with $95 \%$ of the children registered to the insurance fund in our dataset within the first month after birth, we consider the impact of these missing prescriptions on our results negligible. Fourth, misclassification in PCV vaccination coverage might have occurred. However, vaccination coverage was stable and very high (median 95\%) over the entire study period (2006-2013). In 39 out of the 46 municipalities $(85 \%)$ with a vaccination coverage below $90 \%$ in 2012, the fluctuation in coverage over our study period was less than $5 \%$ point. The remaining seven municipalities had only a small number of children and were therefore more prone to larger fluctuations. By categorising vaccination coverage in $5 \%$ point groups, we deem misclassification negligible and to have no important influence on our results. Finally, the variation in PCV vaccination coverage in our study population may have been too small to detect potential effects on antibiotic use across groups.

\section{CONCLUSIONS}

Both crude and time-series analyses of nationwide empirical data suggest that switching from PCV7 to PCV10 resulted in a modest $1.6 \%$ reduction in outpatient antibiotic use in Dutch infants. There was no evidence that $\mathrm{PCV}$ vaccination coverage affected this association, but since the largest purchase RRs were observed in municipalities with the lowest vaccine coverage and had very wide accompanying CIs, our study might have insufficient power to detect such an association.

Acknowledgements The authors gratefully thank Henk Evers and Hugo Smeets (Achmea B.V., The Netherlands) for the provided data extraction services regarding the Achmea health insurance fund and claims database.

Contributors ACF and RPV contributed to the concept and study design, acquisition of data, data analysis and interpretation, drafting of the manuscript, review and final approval of manuscript. RKS contributed to the data analysis plan, the interpretation of the data, wrote portions of the manuscript, review and final approval of the manuscript. EAMS and RAMJD contributed to the data interpretation, wrote portions of the manuscript, review and final approval of manuscript. AMS and AWH proposed the initial study concept and study design, and contributed to data interpretation, drafting of the manuscript, review and final approval of manuscript.

Funding This research received no specific grant from any funding agency in the public, commercial or not-for-profit sectors.

Competing interests ACF is an employee of Seqirus Netherlands B.V., Amsterdam, The Netherlands. Seqirus was not involved in any aspect of the submitted work. EAMS reports independent research grants from GlaxoSmithKline and Pfizer. AWH is chair of a large (around 600 employees) research and teaching institute within our University Medical Center. The Institute performs both investigator-driven and industry-driven research projects with a number of pharmaceutical and diagnostic companies. In addition, some of the members of staff receive unrestricted grants for research projects from a number of companies. It is the institute's explicit policy to work with several companies and not to focus on one or two industrial partners. AWH received no personal payment from any industrial partner. AMS and the evidENT team at University College London have been supported by a NIHR Research Professorship award with the remit to develop a UK infrastructure and programme of clinical trials in ENT Hearing and Balance. The other authors have indicated they have no potential conflicts of interest to disclose.

Patient consent Not required.

Ethics approval The study protocol was approved by the independent scientific advisory committee of Achmea Health Database (protocol number: AHDOC 124).

Provenance and peer review Not commissioned; externally peer reviewed.

Data sharing statement Achmea Health has exclusive rights to all the anonymised individual participant data used in this manuscript. Any requests to (re-)use this data should be directed to the independent scientific advisory committee of Achmea Health database (www.achmea.nl). After approval has been obtained, the statistical analysis plan including all syntaxes, which are stored in our university's data warehouse, will be made available upon request to the corresponding author.

Open access This is an open access article distributed in accordance with the Creative Commons Attribution Non Commercial (CC BY-NC 4.0) license, which permits others to distribute, remix, adapt, build upon this work non-commercially, and license their derivative works on different terms, provided the original work is properly cited and the use is non-commercial. See: http://creativecommons.org/ licenses/by-nc/4.0/

(c) Author(s) (or their employer(s)) [2018]. Re-use permitted under CC BY-NC. No commercial re-use. See rights and permissions. Published by BMJ.

\section{REFERENCES}

1. Goossens H, Ferech M, Vander Stichele R, et al. Outpatient antibiotic use in Europe and association with resistance: a cross-national database study. Lancet 2005;365:579-87. 
2. Hicks LA, Bartoces MG, Roberts RM, et al. US outpatient antibiotic prescribing variation according to geography, patient population, and provider specialty in 2011. Clin Infect Dis 2015;60:1308-16.

3. Otters HB, van der Wouden JC, Schellevis FG, et al. Trends in prescribing antibiotics for children in Dutch general practice. $J$ Antimicrob Chemother 2004;53:361-6.

4. Costelloe C, Metcalfe C, Lovering A, et al. Effect of antibiotic prescribing in primary care on antimicrobial resistance in individual patients: systematic review and meta-analysis. BMJ 2010;340:c2096.

5. Kyaw MH, Lynfield R, Schaffner W, et al. Effect of introduction of the pneumococcal conjugate vaccine on drug-resistant Streptococcus pneumoniae. N Engl J Med 2006;354:1455-63.

6. Wilby KJ, Werry D. A review of the effect of immunization programs on antimicrobial utilization. Vaccine 2012;30:6509-14.

7. Palmu AA, Jokinen $\mathrm{J}$, Nieminen $\mathrm{H}$, et al. Effect of pneumococcal Haemophilus influenzae protein D conjugate vaccine (PHiD-CV10) on outpatient antimicrobial purchases: a double-blind, cluster randomised phase 3-4 trial. Lancet Infect Dis 2014;14:205-12.

8. Lipsitch M, Siber GR. How Can Vaccines Contribute to Solving the Antimicrobial Resistance Problem? MBio 2016;7:e00428-16-16.

9. Laxminarayan R, Matsoso P, Pant S, et al. Access to effective antimicrobials: a worldwide challenge. Lancet 2016;387:168-75.

10. Bernier A, Delarocque-Astagneau E, Ligier C, et al. Outpatient antibiotic use in France between 2000 and 2010: after the nationwide campaign, it is time to focus on the elderly. Antimicrob Agents Chemother 2014:58:71-7.

11. Sox CM, Finkelstein JA, Yin R, et al. Trends in otitis media treatment failure and relapse. Pediatrics 2008;121:674-9.

12. Alpert HR, Behm I, Connolly GN, et al. Smoke-free households with children and decreasing rates of paediatric clinical encounters for otitis media in the United States. Tob Control 2011;20:207-11.

13. Sabuncu E, David J, Bernède-Bauduin C, et al. Significant reduction of antibiotic use in the community after a nationwide campaign in France, 2002-2007. PLoS Med 2009;6:e1000084.

14. Smeets HM, de Wit NJ, Hoes AW. Routine health insurance data for scientific research: potential and limitations of the Agis Health Database. J Clin Epidemiol 2011;64:424-30.

15. Stam J, van Stuijvenberg M, Grüber C, et al. Antibiotic use in infants in the first year of life in five European countries. Acta Paediatr 2012;101:929-34.

16. de Bont EG, van Loo IH, Dukers-Muijrers NH, et al. Oral and topical antibiotic prescriptions for children in general practice. Arch Dis Child 2013;98:228-31.

17. Ivanovska V, Hek K, Mantel Teeuwisse AK, et al. Antibiotic prescribing for children in primary care and adherence to treatment guidelines. J Antimicrob Chemother 2016;71:1707-14.

18. van Lier E, Oomen P, Giebers $\mathrm{H}$, et al. Immunisation coverage National Immunisation Programme in the Netherlands: Year of Report 2015 [In Dutch]: National Institute for Public Health and the Environment (RIVM), 2015. Report No:2015-0067.

19. Ruijs WL, Hautvast JL, van der Velden K, et al. Religious subgroups influencing vaccination coverage in the Dutch Bible belt: an ecological study. BMC Public Health 2011;11:102.
20. Akkerman AE, Kuyvenhoven MM, Verheij TJ, et al. Antibiotics in Dutch general practice: nationwide electronic GP database and national reimbursement rates. Pharmacoepidemiol Drug Saf 2008;17:378-83.

21. Hanquet $G$, Valenciano $M$, Simondon $F$, et al. Vaccine effects and impact of vaccination programmes in post-licensure studies. Vaccine 2013;31:5634-42.

22. Wagner AK, Soumerai SB, Zhang F, et al. Segmented regression analysis of interrupted time series studies in medication use research. J Clin Pharm Ther 2002;27:299-309.

23. Kontopantelis E, Doran T, Springate DA, et al. Regression based quasi-experimental approach when randomisation is not an option: interrupted time series analysis. BMJ 2015;350:h2750.

24. Palmu AA, Rinta-Kokko H, Nohynek $\mathrm{H}$, et al. Impact of national ten-valent pneumococcal conjugate vaccine program on reducing antimicrobial use and tympanostomy tube placements in Finland. Pediatr Infect Dis J 2018;37:97-102.

25. Gefenaite G, Bijlsma MJ, Bos HJ, et al. Did introduction of pneumococcal vaccines in the Netherlands decrease the need for respiratory antibiotics in children? Analysis of 2002 to 2013 data. Euro Surveill 2014;19:20948.

26. Lau WC, Murray M, El-Turki A, et al. Impact of pneumococcal conjugate vaccines on childhood otitis media in the United Kingdom. Vaccine 2015;33:5072-9.

27. van Deursen AMM, Schurink-Van't Klooster TM, Man WH, et al. Impact of infant pneumococcal conjugate vaccination on community acquired pneumonia hospitalization in all ages in the Netherlands. Vaccine 2017:35:7107-13.

28. Knol MJ, Wagenvoort GH, Sanders EA, et al. Invasive Pneumococcal Disease 3 Years after Introduction of 10-Valent Pneumococcal Conjugate Vaccine, the Netherlands. Emerg Infect Dis 2015;21:2040-4.

29. Woudenberg T, van Binnendijk RS, Sanders EA, et al. Large measles epidemic in the Netherlands, May 2013 to March 2014: changing epidemiology. Euro Surveill 2017;22.

30. Lee GC, Reveles KR, Attridge RT, et al. Outpatient antibiotic prescribing in the United States: 2000 to 2010. BMC Med 2014;12:96

31. Håberg SE, Stigum H, Nystad W, et al. Effects of pre- and postnatal exposure to parental smoking on early childhood respiratory health. Am J Epidemiol 2007;166:679-86.

32. de Hoog ML, Venekamp RP, van der Ent CK, et al. Impact of early daycare on healthcare resource use related to upper respiratory tract infections during childhood: prospective WHISTLER cohort study. BMC Med 2014;12:107.

33. Ajetunmobi OM, Whyte $\mathrm{B}$, Chalmers $\mathrm{J}$, et al. Breastfeeding is associated with reduced childhood hospitalization: evidence from a Scottish Birth Cohort (1997-2009). J Pediatr 2015;166:620-5.

34. Neuzil KM, Mellen BG, Wright PF, et al. The effect of influenza on hospitalizations, outpatient visits, and courses of antibiotics in children. N Engl J Med 2000;342:225-31. 